Cortes, K. I., \& Kochenderfer-Ladd, B. (2014). To tell or not to tell: What influences children's decisions to report bullying to teachers. In D. Espelage and S. Low (Guest Eds.). School Climate, Aggression, Peer Victimization and Bully Perpetration. [Special issue]. School Psychology Quarterly, 29, 336-348.

To Tell or not to Tell: What Influences Children's Decisions to Report Bullying to Teachers.

\author{
Khaerannisa I. Cortes ${ }^{\mathrm{a}}$ \\ Becky Kochenderfer-Ladd ${ }^{\mathrm{a}}$
}

AUTHOR AFFILIATION AND ADDRESS:

${ }^{a}$ Arizona State University

T. Denny Sanford School of

Social and Family Dynamics

Tempe, AZ 85287 


\begin{abstract}
Teachers are the primary agents for creating and maintaining a positive classroom climate_ —and promoting healthy interpersonal relations with, and among, their students (including the prevention of school bullying) is key to achieving this goal. For this study, it was posited that students' willingness to report bullying to their teachers is an indicator of the degree to which teachers have successfully created such environments. Data were gathered on 278 (135 boys; 152 girls) ethnically diverse (46.4\% Hispanic; 43.5\% White; 10.2\% Black and Other) 8-to-10 year old students. Results showed that classrooms in which children reported greater willingness to report bullying evidenced lower levels of victimization. Moreover, believing that teachers would take an active role in intervening, such as by separating involved students or involving parents and principals, was associated with greater willingness to report than child level characteristics, such as grade, personal blame, and individuals' propensity toward aggression.
\end{abstract}

KEYWORDS: bullying; peer victimization; classroom climate, anti-bullying programs; social cognitions 


\section{To Tell or Not to Tell:}

What Influences Children's Decisions to Report Bullying to their Teachers?

It is now clear that bullying is a global problem that not only crosses national boundaries, but also gender (Kochenderfer-Ladd \& Skinner, 2002), race (Graham, 2006), and socioeconomic status (Christie-Mizell, 2004) lines. Moreover, researchers have largely dispelled misconceptions that bullying is a normative childhood experience that has no, or minimal, effects on children's adjustment. Specifically, researchers have documented that victimized children are at risk for psychosocial problems including loneliness, low self-esteem and poor social relationships (Ladd \& Troop-Gordon, 2003) as well as suicide, suicidal ideation and nonsuicidal self-injury (Bonanno \& Hymel, 2010; Heilbron \& Prinstein, 2010; Klomek, Marrocco, Kleinman, Schonfeld, \& Gould, 2007). Further, bullied children tend to underperform academically (Juvonen, Wang, \& Espinoza, 2011) and exhibit avoidant behaviors, such as developing negative school attitudes (Kochenderfer \& Ladd, 1996a, 1996b), truancy, absenteeism and dropping out (Otieno \& Choongo, 2010).

In response to the empirical documentation of the harmfulness of peer victimization, along with growing societal pressure for school administrators and educators to take a more active role to stop school bullying, anti-bullying programs have proliferated (see Craig, Pepler, Murphy, \& McCuaig-Edge, 2010; Strohmeier \& Noam, 2012). Consistent with evidence showing that most bullying takes place within school (Batsche \& Knoff, 1994; Hawkins, Pepler, \& Craig, 2001), programs are typically aimed at creating positive classroom and school climates where children feel welcome (e.g., sense of belonging; Goodenow, 1993) and safe from physical and psychological harm. Toward such aims, teachers are typically the primary agents for creating 
and maintaining positive climates within their classrooms as well as across school contexts (e.g., hallways, lavatories, lunchrooms; playground); promoting healthy interpersonal relations with, and among, their students is key to successfully achieving this goal. For the current study, it was posited that the degree to which teachers have successfully created positive, caring and safe environments can be inferred by how willing and comfortable students are reporting bullying to them (e.g., seek their help). Moreover, consistent with this proposition, it was expected that bullying would be less prevalent in classrooms where children are willing to report victimization to their teachers.

It was further proposed that children's willingness to report bullying is influenced by the relational schemas they have developed regarding how serious their teachers are about intervening in bullying problems. In other words, the premise of this study was that, by observing teachers' interactions with others as well as seeing how they respond to peer conflict and bullying, youth develop relational schemas of their teachers as either caring, helpful and effective at handling such situations, or as uncaring and unhelpful (see Troop-Gordon \& Quenette, 2010 for a similar argument). Support for this premise can be found in a study conducted by Aceves and colleagues (Aceves, Hinshaw, Medonza-Denton, \& Page-Gould, 2010) who found that teachers' helpfulness in resolving past bullying episodes encouraged victimized children to seek them out for help. Such findings suggested that students notice how teachers respond to bullying, and use this information to decide on how likely the teacher is to help them if they are in that situation. Hence, if teachers have successfully created a supportive classroom environment, youth would develop relational schemas of their teachers as helpful and sympathetic to victims of bullying, and would thus be more likely to seek them out for help. 
Moreover, it is likely that bullying would be less prevalent in classroom where teachers are perceived by students as taking reports of bullying seriously. In contrast, students' relational schemas of teachers as uninvolved or unconcerned with bullying could be viewed as a sign of an unsupportive classroom environment where bullying is ignored and allowed to persist.

Thus, the focus of this investigation was on children's willingness to tell their teachers about bullying because student reports of bullying are critical to efforts to improve classroom climate and reduce school bullying. Indeed, reporting bullying may be the first, and in some cases only, step toward stopping victimization. For example, although teachers' interventions can prevent subsequent bullying (Nicolaides, Toda, \& Smith, 2002; Yoon \& Kerber, 2003), researchers (Crothers, Kolbert, \& Barker, 2006; Novick \& Isaacs, 2010) have found that, without significant awareness-raising efforts and specific training in the identification of bullying, teachers often do not recognize some interactions as bullying (e.g., see it as teasing) or are otherwise unaware of the bullying that takes place. Moreover, even when teachers witness clear cases of bullying, they are often reluctant to intervene either because they feel unprepared to respond effectively or because they are not sure if the victimized students would welcome their help (Novick \& Isaacs, 2010). Thus, although teachers are likely to intervene when they feel the bullying is serious (e.g., physical, bodily harm; Craig et al. 2000, Yoon \& Kerber, 2003), in many cases, they are not likely to intervene unless students approach them directly for help (Novick \& Isaacs, 2010). Thus, it becomes critical that teachers have created a climate in which children feel comfortable and safe to approach them about bullying. 


\section{Teacher Responses to Bullying Schemas as Predictors of Reporting}

Consistent with the argument that children develop cognitive representations of others' characteristics and behavioral propensities that then influence their social interactions (e.g., Dweck \& London, 2004), it was hypothesized that children develop schemas about their teachers that influence the likelihood of whether or not they would tell their teachers about bullying problems and seek their advice or assistance. To test this general hypothesis, children's relational schemas of their teachers' responses to bullying were assessed by asking students what they believe their teachers would do if bullying occurred. The relational schemas, referred to as Teacher Responses to Bullying Schemas (TRBSs), tap five distinct strategies: 1) telling the victim to ignore the harasser, 2) encouraging the victimized child to assert him or herself, 3) separating the bully and victim, 4) punishing the bully, and 5) involving parents. Then, the hypothesis that students would be more likely to involve teachers if their TRBSs reflect teachers as taking a direct and active role in intervening on their behalf because such responses may be viewed as more caring and helpful (e.g., their reports are being taken seriously) was examined. Specifically, because TRBSs of separating victims and aggressors, punishing aggressors, and involving parents are direct actions demonstrating that bullying is being taken seriously and the teacher is taking active steps to stop bullying, such TRBSs were expected to correlate positively with students' willingness to tell the teacher. In contrast, passive TRBSs, such as advising the victim to either ignore the bully or to stand up for oneself were hypothesized to reflect unsympathetic and unhelpful expectations of teachers' responses; thus, such TRBS were expected to predict less likelihood of seeking teachers' assistance. 


\section{Child-level Factors that Predict Reporting}

Although the premise of this study was that teachers have the primary responsibility for creating positive classroom climates that encourage students to report bullying, it is likely that individual children may nevertheless have characteristics that deter them from reporting bullying despite teachers' sincere desire to help and intervene. For example, self-presentation theory (Baumester, 1982; Leary \& Kowlaski, 2005) argues that children learn very early to project an image of themselves that is consistent with their groups' values of social desirability. Moreover, the desire to be viewed favorably by others (i.e., teachers in this study) would decrease the likelihood that one would risk drawing attention to one's own negative behaviors or traits. Thus, it was hypothesized that children who tend to pick on, or harass, others or who believe they have acted in ways which incite their peers' aggression, would be less likely to report bullying to teachers lest it bring unwanted attention to their own culpability in contributing to a hostile classroom climate. In other words, children's tendency toward peer aggression, or self-blame for provoking aggression, were expected to decrease the likelihood of reporting bullying in attempts to preserve their image of individuals who conform to the teachers' values and expectations for classroom and interpersonal behavior.

Similarly, children, especially boys, may be motivated to convey an image of selfreliance (e.g., a desired trait for boys and older children), such that they are capable of handling peer problems on their own. Support for this contention can be culled from findings demonstrating that boys and older children are less likely to disclose social problems (Rose et al., 2012). Thus, it was further hypothesized that boys and older children would be less willing to involve teachers compared to girls and younger students. 
Finally, Oliver and Candappa (2007) found that students who have close relationships with their teachers are more likely to seek their help. Thus, children who have a close (e.g., trusting, warm) relationship with their teachers were expected to be more likely to report bullying to their teachers (see Eliot, Cornell, Gregory, \& Fan, 2010 for a similar argument). Support for this hypothesis can be culled from

\section{Summary}

In sum, it is argued that the quality of the classroom climate may be partially reflected by students' willingness to report bullying to their teachers, such that classrooms in which teachers have successfully conveyed concern for their students and taken a clear stance against bullying, will not only have lower levels of bullying, but will also evidence greater student willingness to report such incidents. Moreover, it was hypothesized that TRBSs indicative of active and direct responses, such as separating students, punishing or reprimanding aggressors and involving parents, would predict higher levels of reporting than those that place the onus of dealing with the bullying back on the student (e.g., advocating ignoring or assertion). Lastly, despite the actual classroom climate, children's desire to present a favorable image to teachers, as well as to avoid the risk of bringing unwanted attention to their own culpability in contributing to a negative classroom climate, children's propensity toward aggression, self-blame for provoking aggression, as well as gender and age norms, were expected to influence children's willingness to report bullying. 


\section{Method}

\section{Participants}

Thirty-eight 3rd and 5th grade teachers in four participating schools from three school districts in the Southwest United States agreed to provide data on their students. Parental consent forms, in both English and Spanish, were sent home with over 600 third and fifth grade children. Although permission was obtained for 283 students, 4 of the teachers had only one or two participating students each (range: 1 to 16 students per class), so their classes (and 5 students) were dropped from this study ( $n=34$ classrooms, $M$ students per class $=8.14$; number of participating students in each of the four schools were 55, 58, 76 and 94). Thus, data are reported for $278\left(603^{\text {rd }}\right.$ grade boys and $663^{\text {rd }}$ grade girls; $755^{\text {th }}$ grade boys and $775^{\text {th }}$ grade girls) ethnically diverse children (46.3\% Hispanic or Mexican American; $43.5 \%$ White/Caucasian; 10.2\% Black, Native American, Asian American, biracial and others). The socioeconomic status of the sample was estimated to be low-to-middle income based on eligibility for reduced or free lunches (i.e., $26 \%, 56 \%, 79 \%$ and $95 \%$ of students in such programs at the four schools).

\section{Procedures}

The study was conducted in compliance with the Internal Review Board and data were gathered in Spring 2006 when children were in third and fifth grade. As there were a significant number of Spanish-speaking and bilingual students present in the sample, child questionnaires were written in both English and Spanish. During classroom administrations of questionnaires, both English- and Spanish-speaking interviewers were available to answer questions and to assist individuals who needed extra help completing the measures. Prior to administration of the 
questionnaires, students were informed that their answers would be private and not shared with other students, parents, or school staff. Students were then asked whether they assented to participate in the study, and given the opportunity to decline to participate. Students were instructed not to talk to one another or share their answers with other students. A small schoolrelated gift was given to students for participating in the project. Teachers also completed questionnaires, and received a monetary payment based on the number of students participating in their class (\$5 per child).

\section{Measures}

Telling teachers. The degree to which children would be willing to involve their teachers if bullying occurred was assessed using a subscale of the What I Would Do measure (Kochenderfer-Ladd and Pelletier, 2008). This measure includes 27 strategies for coping specifically with bullying; three items tap involving teachers: (a) tell the teacher what happened, (b) ask the teacher what to do, and (c) get help from a teacher. Children used a 4-point scale (1= never; $2=$ sometimes; 3 = most of the time; and 4 = every time) to rate how often they would get help from a teacher if they were bullied. Items were averaged to create a single score $(M=2.36$, $S D=.92)$, and the scale showed adequate reliability $(\alpha=.84)$.

Teacher Responses to Bullying Schemas (TRBS). Children's perceptions of how their teachers would intervene in bullying episodes were assessed using the Perceived Teacher Response Scale (Troop-Gordon \& Quenette, 2010). Specifically, children were given the prompt, "If your teacher caught someone picking on or being mean to another kid how often $(1=$ never; $2=$ sometimes; $3=$ most of the time; and $4=$ every time) would he or she...?" Both exploratory and confirmatory factor analyses conducted on the original 20-item measure 
revealed five distinct scales with 4 items each (Troop-Gordon \& Quenette, 2010). For this study, 4 additional items were added to create a new scale to indicate that teachers take an active role by separating students who are involved in bullying as the aggressor and victim. Exploratory factor analyses on the modified 24-item measure revealed a six-factor structure; however, one of the advocate independent coping items loaded alone (i.e., "say s/he won't get involved"), so it was dropped from the measure. The remaining 23 items loaded on five distinct factors (note that the remaining 7 advocate assertion and independent coping items loaded together in this study), and are labeled: a) advocate avoidance (4 items, e.g., tell the kid getting picked on to ignore it; $\alpha$ $=.72 ; M=2.30, S D=.71)$; b) advocate assertion ( 7 items, e.g., tell the kid being picked on to stand up for themselves; $\alpha=.74 ; M=1.72, S D=.61$ ); c) separate students (4 items, e.g., make the kids to stay away from each other; $\alpha=.78 ; M=2.66, S D=.83$ ); d) punish aggressors (4items, e.g., yell at the students who are picking on the kid; $\alpha=.60 ; M=2.34, S D=.84$ ); and e) contact parents ( 4 items, e.g., let the parents know that their kids were being mean; $\alpha=.73 ; M=$ $2.57, S D=.76)$.

Personal behavior blame. The Why Bad Things Happen measure (see Visconti, Ladd \& Clifford, 2013, for psychometrics and evidence of validity for entire measure) was administered to assess the degree to which children blame their own behavior for being victimized. Specifically, students used a four-point scale $(1=$ never; $2=$ sometimes; $3=$ usually; and $4=$ always) to indicate how plausible each reason is for why they may be targeted for peer aggression. Four of the 20 possible causes refer directly to personal behavior attributions (i.e., $I$ did something mean to them; I did something they didn't like; I did something wrong; I did 
something annoying). Scores were computed by averaging across the four relevant items and showed adequate reliability $(\alpha=.70 ; M=1.47, S D=.52)$.

Picks on others. Children were provided a list of their classmates and asked to rate how much each classmate "picks on others" using a four-point scale: $(1=$ never; $2=$ rarely; $3=$ some of the time; and $4=$ a lot of the time). This peer rating item was created specifically for this study (Kochenderfer-Ladd, 2003) and, as evidence of validity, correlated negatively with peer acceptance $(r=-.26, p<.001)$. Picks on Others scores were computed by averaging peers' responses (range 1.00 to $3.15 ; M=1.53, S D=.47$ ), such that each student received an averaged score based on all their classmates' responses.

Quality of teacher-student relationship (TSR). Pianta's (1991) measure was used to assess the closeness of the teacher-student relationship (TSR). Specifically, teachers used a fourpoint scale ( $1=$ really not true; $2=$ somewhat untrue; $3=$ somewhat true; and $4=$ really true $)$ to indicate the warmth/closeness of their relationships with their students. The closeness scale is comprised of 8 items, such as "I share a warm relationship with this student." Ratings were averaged across items and the scale evidenced adequate reliability $(\alpha=.83 ; M=3.14, S D=.58)$.

Peer victimization. The self-reported scale of the Multi-Source Peer Victimization Inventory (MSPVI; Ladd \& Kochenderfer-Ladd, 2002) was used to assess peer victimization. Students used a four-point scale $(1=$ never; $2=$ rarely; $3=$ some of the time; and $4=\mathrm{a}$ lot of the time) to rate how often they experienced four forms of victimization: (a) general victimization (e.g., pick on you); (b) verbal (e.g., call you mean names or say hurtful things to you); (c) physical (e.g., hit or push you); and (d) say mean things or lies about you to other kids. Scores were computed by averaging across the four self-report items $(\alpha=.79 ; M=1.74, S D=.73)$. 


\section{Results}

After evaluating data missingness and determining the extent of school and classroomlevel dependency, preliminary analyses were conducted to examine: a) the distinctiveness of the study scales and b) the bivariate relations among all the variables. Next, K-Means analyses were used to test the hypothesis that classroom-levels of student willingness to report bullying is associated with lower prevalence of victimization followed by an examination of mean-level differences in the study variables as a function of gender, grade and classroom climate. Finally, regression analyses were conducted to examine which of the hypothesized factors contributed uniquely to variation in students' willingness to report bullying to their teachers.

\section{Data missingness}

Data missingness was examined and the average overall rate was $<1 \%$. Specifically, missing data were found for only two of the study variables and affected less than $5 \%$ of the sample: two students were missing teacher ratings of the closeness of the student-teacher relationship and 12 were missing peer ratings of "picks on others." Because no other variables were missing data, data were not considered to be missing at random, and consequently, no imputation procedures were employed; however, the missing data points were replaced with the series means for the two variables.

\section{Within School and Classroom Dependency}

To examine within school- and classroom-level effects (teacher effects), intraclass correlation coefficients were computed. ICCs of $.05, .10$ and .15 can be considered small, medium and large, respectively (Hox, 2002), and design effects $>2.00$ indicate dependency. A school-level effect was found only for "picks on others" (ICC = .07; Design Effect = 5.89); all 
other ICCs were $<.03$. ICCs for classroom effects ranged from .03 to .22 with medium effects found for telling the teacher $(\mathrm{ICC}=.13)$ and "picks on others" ratings $(\mathrm{ICC}=.12)$. Large effects were found for close TSRs (ICC $=.16$; Design Effect > 2.00) and the TRBSs for assertion (ICC $=.22$; Design Effect $>2.00$ ). Because school and classroom-level effects were found, their effects were controlled for in subsequent analyses.

\section{Preliminary Examination of Study Variables}

Bivariate correlations were conducted separately by grade and by sex to examine the distinctiveness among the scales as well as to explore the bivariate relations among the variables. Whereas the pattern of correlation was similar for $3^{\text {rd }}$ and $5^{\text {th }}$ graders, differences were found for boys and girls; thus, correlations are reported separately by sex in Table 1 .

Distinctiveness of subscales. Low to moderate correlations among the predictor variables indicated the scales tap distinct constructs (see Table 1). It is important to note that although personal behavior blame was significantly and positively related to picking on others, the low correlations for both sexes $(r=.25)$ indicate that caution is warranted against equating personal behavior to aggression. Rather, personal behavior blame, in this study, referred to behaviors that children may believe are annoying, wrong, or disagreeable to peers.

Correlates of telling the teacher. For both boys and girls, TRBSs of believing teachers would separate students and involve parents were positively associated with telling teachers if they were bullied (see Table 1). However, differences were also found such that picking on others was negatively associated with telling the teacher only for boys. Interestingly, passive TRBSs (i.e., advocating ignoring and assertion) were positively correlated with telling the 
teacher-and this was statistically significant for girls only. No other correlations were significantly associated with students' willingness to report bullying.

\section{Willingness to Report Bullying as an Indicator of Classroom Climate}

To examine the argument that students' willingness to tell their teachers about bullying could be construed as an indicator of a safe and caring classroom context, K-means analyses were used to determine if classrooms could be grouped into positive supportive climates (i.e., high levels of reporting and low levels of self-reported peer victimization) or negative, unsupportive ones (i.e., low levels of reporting; high levels of self-reported peer victimization). Toward this aim, students' scores for reporting bullying to their teachers and self-reported peer victimization were averaged within the 34 classrooms, and then standardized scores were used in the analyses.

To identify the optimal number of clusters, successive numbers of cluster solutions were compared to see if the addition of another grouping reduced within-cluster variability (i.e., paired-samples t-tests were used to compare the mean distance scores for each cluster solution; see Wishart, 1982). Results indicated that the hypothesized 2-cluster solution best fit the data; that is a 3-cluster solution did significantly reduce within-cluster variability $\left(\mathrm{t}_{(34)}=1.56, p>.05\right)$. Moreover, the first cluster consisted of 17 classrooms in which students were willing to tell teachers about bullying $(\mathrm{z}$-score cluster center $=.82)$ and self-reported peer victimization was low (z-score cluster center $=-.30)$, and the second cluster comprised the remaining 17 classrooms in which students were less willing to tell $(z$-score cluster center $=-.78)$ and peer victimization was more prevalent $(z$-score cluster center $=.28)$. These findings were consistent with the view that students' willingness to tell the teacher reflects a positive classroom 
environment where children are encouraged to report bullying, and victimization is less likely to occur. The resultant clusters were saved and used in subsequent analyses to further examine, as well as control for, classroom-level effects.

Examination of mean-level differences. To examine possible mean differences among study variables, a 2 (gender: boys/girls) x 2 (grade: $\left.3^{\text {rd }} / 5^{\text {th }}\right)$ x 2 (climate: positive/negative) MANOVA was conducted in which all possible two-way and three-way interactions were tested. No two-way or three-way interactions were statistically significant; thus, only main effects are reported (see Table 2 for means and standard deviations by grade and sex).

Omnibus tests revealed significant main effects for sex (Wilks' Lambda $F[9,263]=4.20$, $p<.001$ ), grade (Wilks' Lambda $F[9,263]=2.00, p<.05$ ), and classroom climate (Wilks' Lambda $F[9,263]=3.73, p<.001)$. Univariate $F$-tests revealed main effects $(p<.05)$ of sex for: (a) telling the teacher, $F(1,271)=10.20$, (b) personal behavioral blame, $F(1,271)=4.17$, (b) picks on others, $F(1,271)=10.13$, (c) close teacher-student relationship, $F(1,271)=15.10$, and (d) separate TRBS, $F(1,271)=4.70$. Specifically, consistent with the study hypothesis, girls were more likely to report bullying to their teachers (see Table 2). In addition, boys were more likely to blame their own behavior and to be rated higher on "picks on others" whereas girls were more likely to have a closer relationship with teachers. Finally, girls reported higher levels of believing teachers would separate bullies and victims.

Main effects for grade were found for picks on others, $F(1,271)=4.04$ and TRBS of assertion, $F(1,271)=9.18$ such that older children were rated more highly on picks on others and were less likely to believe teachers would tell them to assert themselves (see Table 2). 
The main effect for classroom climate, $(F(1,271)=26.67, p<.001)$, was limited to the variable used for group formation; namely, the positive classroom climate group had a higher mean for telling the teacher $(M=2.77 ; S D=.89)$ than the negative classroom climate group $(M$ $=2.05 ; S D=.82)$.

\section{Unique Predictors of the Likelihood Students will Report Bullying to their Teachers}

To determine which factors contributed uniquely to the prediction of telling teachers, a two-step hierarchical regression analyses was conducted. School, classroom climate (coded $1=$ positive climate; $2=$ negative climate), grade $\left(1=3^{\text {rd }}\right.$ grade and $2=5^{\text {th }}$ grade $)$ and sex $($ coded $1=$ boys; 2 = girls) were entered on Step 1 followed by all the individual predictor variables (i.e., personal behavioral blame, picks on others, close TSR, and the five TRBSs) on Step 2.

Unstandardized beta weights on Step 2 are reported in Table 3. Consistent with hypotheses, children in the positive classroom climate (negative $\beta$ weight) and girls (positive $\beta$ weight) were more likely to tell teachers. Also consistent with the hypotheses, more active forms of teacher responses (TRBSs of separating students and involving parents) were positively predictive of reporting bullying. However, contrary to expectations, but not entirely surprising, believing that teachers would punish aggressors was negatively predictive of telling the teacher.

\section{Discussion}

Anti-bullying programs often emphasize the importance of reporting bullying to adults and teachers are a natural choice given their proximity to where bullying is likely to occur (e.g., areas within the school context), the amount of time spent with students, and their role in implementing program components and ensuring a safe and welcoming classroom climate. The premise of the present study was that children's willingness to report bullying to teachers could 
be construed as an indicator of teacher success in creating a positive support classroom environment where bullying is taken seriously. Results were consistent with this premise, such that classrooms could be divided into those characterized by high levels of willingness to report bullying coupled with lower levels of self-reported victimization and those characterized by less willingness to involve teachers coupled with greater frequency of victimization. Moreover, results suggested students' expectations for how teachers would respond to bullying were stronger predictors than other factors, including sex, grade, personal blame, and one's own level of aggressiveness. These findings are discussed in greater detail in the following sections.

\section{Classroom Climates Associated with Lower or Higher Levels of Peer Victimization}

In support of the proposition that students' willingness to report bullying could be an indication that teachers have successfully created positive and supportive classroom contexts in which children feel comfortable approaching their teachers about social problems (especially bullying), results from this study revealed that greater likelihood of telling teachers about bullying was linked with lower levels of classroom victimization. Specifically, cluster analytic procedures indicated that classrooms could be distinguished as either positive (high telling, low victimization) or negative (low telling; high victimization) classroom climates. This finding is particularly interesting given that it would not be unreasonable to expect that higher levels of reporting on bullying incidents would be associated with correspondingly higher prevalence of peer victimization; that is, children could be expected to tell their teachers about bullying because so much of it is happening. Thus, these findings offers promising support for the conclusion that when teachers effectively create classroom climates where it is clear that bullying is not accepted and students are encouraged to report such incidents (and presumably 
believe that their reports are taken seriously), their classrooms evidence lower levels of victimization. In contrast, in classrooms where children are hesitant to report bullying, or have discovered that such reports are dismissed, bullying and peer victimization are allowed to persist and perhaps even to thrive. It should be mentioned, however, that although this study offers evidence to support recommendations for students to report bullying to teachers, there is the underlying assumption that teachers have created classroom climates that reward such reporting with swift and effective action consistent with the attitude that bullying is not acceptable and that such reports will be taken seriously.

\section{Predictors of Students' Reporting Bullying to Teachers}

Teacher responses to bullying schemas (TRBSs). Preliminary evidence was found to support the proposition that children develop relational schemas of their teachers that influence the likelihood that they would involve teachers when bullying occurs. Specifically, the results not only indicated that children hold TRBSs that can be reliably assessed, but that TRBSs were predictive of telling the teacher about bullying. Moreover, as discussed below, these expectations for teachers' responses were stronger predictors than children's own personal characteristics. Findings from this study offer further support for the hypothesis that children develop cognitive representations of individuals based on past experiences which influence their future behavior and social interactions (e.g. London \& Dweck, 2004). Specifically, distinct TRBSs were identified that were differentially related to students' willingness to tell their teachers about bullying. These findings suggest that children are sensitive to social cues in the classroom and have incorporated such experiences into their relational schemas. Moreover, evidence that some teacher responses are viewed by students as more helpful, caring or active 
can be inferred by their differential associations with children's willingness to involve their teachers in bullying situations. For example, expectations (TRBSs) that teachers would respond to reports of bullying by actively intervening — either by keeping the bully away from them (i.e., separating students involved) or by involving parents - appear to be viewed by children as helpful strategies based on findings that these TRBSs were unique predictors of greater likelihood of telling teachers.

Although longitudinal studies are still needed to determine if these are actually effective strategies at reducing bullying, or are merely evidence of children's perceptions that their teachers are taking their predicament seriously, prior research suggests that these are promising strategies. For example, a study conducted by Kochenderfer-Ladd and Pelletier (2007) showed that classrooms in which teachers reported involving parents in bullying cases evidenced lower levels of victimization. Moreover, anti-bullying programs often include a parental component as part of their overall intervention strategy (Smith, Schneider, Smith, \& Ananiadou, 2004); however, studies are still needed to examine the effectiveness of such involvement and to determine what the nature of such involvement should entail. Further, the effectiveness of such strategies should be monitored, because if they are ineffective, youth may incorporate these experiences into their TRBSs and reconsider their willingness to report bullying.

In contrast to TRBSs of separating students and involving parents, believing the teacher would punish the victim appeared to be viewed by youth as undesirable or unhelpful. Specifically, the TRBS of punishing bullies was associated with less likelihood of telling the teacher. Researchers, such as Oliver and Candappa (2007), have found that children worry they would be ridiculed by their peers for reporting the bullying, and fear the bullying would worsen, 
especially if the bully were punished. It is not difficult to imagine victims' being reluctant to tell teachers who may not only be unable to stop the victimization, but may, in fact, make it worse. Thus, recommendations for punishing bullies should be made with caution and with care to protect victims from repercussions. For example, it may be important to assure potential reporters that punishment would be a last resort, and that attempts would be made, if possible, to protect the identity of the reporting child. Moreover, such findings have serious implications for prevention and intervention programs that require punishment or implement a "zero tolerance" policy suggesting such strategies may further deter students' from reporting incidences to adults. Interestingly, believing teachers would advocate assertion or ignoring bullies were not necessarily deterrents to telling teachers. That is, although they were not unique predictors of telling the teachers, for girls, they were significant positive correlates. A potential explanation for the null findings is that the underlying processes may be different for boys and girls. For example, it may be that, for girls, telling teachers about bullying is not just about getting help to stop victimization, but also reflects their need for sympathy and emotional support. Such supposition would be consistent with the hypothesis that seeking social support in distressing situations is more socially acceptable for girls than for boys, and perhaps offers a sense of wellbeing and comfort to girls that are not as likely to be found by boys.

Child-level factors. Despite teachers' best efforts, and even in the most positive of classroom climates, individual child characteristics may influence students' willingness to report bullying. For example, based on self-presentation theory (e.g., Baumeister, 1982), it was hypothesized that children who are either predisposed to picking on others or who blame their own behavior for being targeted for aggression would not be inclined to bring bullying to their 
teachers' attention for fear of being viewed unfavorably themselves. Although neither one emerged as unique predictors of telling the teacher, peer ratings for boys' tendency to pick on others were associated negatively reporting bullying incidents. It may be that boys who themselves pick on others are especially motivated to avoid drawing attention to their own bullying-related behaviors so that they can convey a positive image (e.g., behaviorally appropriate, socially competent) of themselves to teachers. It could also be that such boys may view their own aggressive behavior as standing up for themselves, or fighting back; thus, they would not believe they need to involve teachers. In other words, what peers report as "picking on others", some boys may construe as a legitimate coping strategy for handling bullying on their own. In either event, intervention programs that stress involving an adult may not be as effective for boys who see aggression as an appropriate behavior for solving peer problems and responding to bullying. Anti-bullying programs may need to counteract beliefs that aggression is an effective way to handling bullying, and encourage them to share their experiences of bullying with adults to gain assistance or advice for alternative responses.

Findings were consistent with the hypothesis that girls would be more comfortable telling teachers about bullying. Such findings are consistent with arguments that it is more socially acceptable for girls to seek support for social problems whereas boys are expected to stand up for themselves and cope independently. Moreover, there seems to be empirical evidence that such support seeking may be more beneficial for girls than for boys. For instance, in a study conducted by Kochenderfer-Ladd and Skinner (2002) seeking social support for dealing with bullying was a protective factor for victimized girls, but increased victimized boys' risk for peer rejection. Thus, efforts to encourage boys to involve teachers in bullying may inadvertently 
harm boys' peer relationships; consequently, it would be important for researchers to either determine how teacher interventions could be improved to be more helpful for boys or to identify alternative strategies that may be more effective (and socially appropriate) for boys. However, without such alternatives, boys may need special encouragement to report bullying and extra assurances that bullying is not a typical form of peer problem that can be easily stopped by one's own volition, and that it is not a sign of weakness to seek help.

Although previous research suggests that younger children are more likely than older students to tell teachers about bullying (Aceves et al., 2010; Kochenderfer-Ladd \& Pelletier, 2008), no grade effect was found. Specifically, although the trend was for younger children to report greater likelihood of telling the teacher, $3^{\text {rd }}$ graders were no more likely than $5^{\text {th }}$ graders to report bullying incidents. It is likely that by third grade, children may not be considered "young" as compared to the kindergarten or first grade children studied in prior investigations. In other words, by third grade, children may no longer be as strongly encouraged to involve adults in social problems, and may have been socialized to believe that involving teachers in peer problems is "childish", "socially immature" or tantamount to tattling. Moreover, by third grade, children may already be attempting to present themselves to others as capable of handling bullying on their own, and thus, as sufficiently self-reliant to no longer need adult assistance.

Similarly, it may be that, by third grade, children have had more experience with handling bullying than younger children, and thus, do not feel the need to involve teachers. Nevertheless, this should not be taken to imply that anti-bullying programs should stop advising students to report bullying; rather youth of all ages should be taught how to distinguish peer conflicts that do not necessitate adult intervention from bullying which does. Moreover, as 
children mature, they may need special assurances that bringing bullying to an adults' attention is not tattling or showing weakness or immaturity; but rather the start of a process to end ongoing harassment not only for themselves but for others who are also in the same predicament (e.g., they are helping others who are bullied by reporting their own experiences).

Lastly, close teacher-student relationships (TSR) were anticipated to be a predictor of reporting bullying as students who share a positive relationship with their teachers may be more willing to confide in them. Researchers have consistently shown that the quality of the relationship forged between teachers and their students plays a role in youth's adjustment in school (Hamre \& Pianta, 2001; 2005; Birch \& Ladd, 1997; 1998) and that caring teachers are important to students' development at all ages. However, contrary to expectations and to previous research (Oliver \& Dandappa, 2007), close TSRs were not correlated with telling the teacher. In all likelihood the inability to detect such association is due to a ceiling effect in which teachers tended to report having positive relationships with their students $(M>3.00$ on 4point scale). While this is good news, and teachers seem to be aware of the importance of establishing high quality relationships with their students, it would be important to consider the quality of the relationship from the students' point of view in future investigations.

\section{Limitations and Implications}

Although, Baldwin (1997) has argued that relational schemas are most reliably assessed through self-reports, some may argue that shared method variance may be problematic because children self-reported on their experiences with victimization, perceptions of their teachers' responses to bullying and likelihood of telling the teacher. However, while acknowledging the limitation, the theoretical rationale for this study was based on children's cognitive 
representations of their teachers' and the extent to which those schemas would predict telling teachers about bullying. Moreover, this study incorporated the perspectives of others, such that teachers reported on the closeness of their relationships with individual students, and peer reports were obtained on students' propensity to pick on others. Finally, regression analyses in which the potential predictors are entered simultaneously into the equation to determine the unique contribution each makes to the prediction of telling the teacher should allay some of the concern over results being biased by shared method variance.

Another potential limitation is that the study relied on cross-sectional data gathered at a single point in time and thus does not allow for conclusions of causal priority. Clearly additional research, using more time points, over longer periods of time, is warranted. Moreover, such studies may offer insights into the development of children's TRBSs and the experiences upon which they are based. For example, it could be argued that children's perceptions of how their teachers would respond are erroneous or are based on experiences with previous teachers and hence they may not really know what their current teacher would do. Additional studies could shed light on the association between what students' think their teachers would do, what teachers report doing, and what observers' witness teachers doing, when bullying occurs.

Despite these potential limitations, the current study addressed a very timely and pertinent question of what may influence whether or not children tell their teachers about bullying. Consequently, results from this study have important implications for anti-bullying policies and intervention strategies. For instance, significant sex differences suggest that boys may need more encouragement than girls to report bullying. Moreover, school policies that focus only on punishing bullies may need to be reconsidered and focus could be shifted toward 
less punitive strategies first, such as separating involved children, providing victims with safe places to spend free time, and involving parents in stopping their children from picking on and bullying others.

In general, findings support the importance of teachers in creating classroom climates that encourage the reporting of bullying and convey to students that such reports would be taken seriously and direct action would be taken. Results suggest that children are picking up such messages and they are likely to respond in ways that are consistent with their expectations for how bullying will be dealt with. This is especially important, as intervention efforts cannot be employed if adults are not aware of the bullying that exists—and that the primary way adults learn of bullying is through students' reports. Thus, although there does appear to be real risks associated with informing teachers (e.g., retaliation; Oliver \& Candappa, 2007), teachers remain the central figure for intervening in school bullying. Of particular importance is that they represent the adult in the classroom with the moral obligation to ensure the safety of their students as well as the authority to take direction action and socialize all their students in appropriate behavior. 
Table 1

Correlations Among Measures

$\begin{array}{lllllllllllll}\text { Measures } & 1 & 2 & 3 & 4 & 5 & 6 & 7 & 8 & 9 & 10\end{array}$

\begin{tabular}{|c|c|c|c|c|c|c|c|c|c|c|}
\hline 1 Tell teacher & & -.11 & $-.25^{*}$ & .15 & .05 & .15 & .15 & $.40^{*}$ & .03 & $.32^{*}$ \\
\hline 2 Personal blame & -.08 & & $.25^{*}$ & -.12 & $.29^{*}$ & -.06 & .08 & .09 & .11 & .03 \\
\hline 3 Picks on others & -.02 & $.22^{*}$ & & -.15 & $.18^{*}$ & .00 & .09 & .01 & .09 & -.04 \\
\hline 4 Close $\mathrm{TSR}^{1}$ & -.01 & .08 & $-.23^{*}$ & & -.03 & .02 & -.09 & -.05 & .04 & .06 \\
\hline 5 Peer victimization & -.09 & $.40^{*}$ & $.32^{*}$ & -.04 & & .01 & .05 & .10 & .12 & .02 \\
\hline 6 Advocate avoidance & e. $33^{*}$ & -.07 & -.04 & -.07 & .04 & & $.32^{*}$ & $.43^{*}$ & $.34^{*}$ & $.52^{*}$ \\
\hline 7 Advocate assertion & $.18^{*}$ & .07 & -.09 & $.17^{*}$ & .05 & $.48^{*}$ & & $.20^{*}$ & $.31^{*}$ & .06 \\
\hline 8 Separate students & $.23^{*}$ & -.04 & -.02 & -.02 & .00 & $.36^{*}$ & $.20^{*}$ & & $.49^{*}$ & $.62^{*}$ \\
\hline 9 Punish aggressor & .08 & .05 & .02 & .01 & .12 & .12 & .07 & $.21^{*}$ & & $.46^{*}$ \\
\hline 10 Involve parents & $.42^{*}$ & -.01 & -.01 & -.04 & .08 & $.31^{*}$ & $.18^{*}$ & $.46^{*}$ & $.52^{*}$ & \\
\hline
\end{tabular}

Note. Correlations for boys $(n=135)$ are above the diagonal; girls $(n=143)$ are below. ${ }^{*} p<.05$.

${ }^{1} \mathrm{TSR}=$ Teacher-Student Relationship. 
Table 2

Means (Standard Deviations) by Grade and Sex

\begin{tabular}{|c|c|c|c|c|}
\hline Variable & Grade 3 & Grade 5 & Boys & Girls \\
\hline Tell teacher & $2.63(.93)$ & $2.13(.85)$ & $2.19(.91)^{\mathrm{a}}$ & $2.52(.90)^{b}$ \\
\hline \multicolumn{5}{|l|}{$\mathrm{TRBSs}^{1}$} \\
\hline Tell to ignore & $2.35(.78)$ & $2.26(.65)$ & $2.26(.71)$ & $2.33(.72)$ \\
\hline Tell to assert & $1.88(.66)^{\mathrm{a}}$ & $1.59(.54)^{b}$ & $1.72(.64)$ & $1.73(.58)$ \\
\hline Separate students & $2.70(.87)$ & $2.62(.79)$ & $2.55(.81)^{\mathrm{a}}$ & $2.76(.83)^{\mathrm{b}}$ \\
\hline Punish aggressor & $2.26(.90)$ & $2.46(.78)$ & $2.42(.87)$ & $2.32(.81)$ \\
\hline Involve parents & $2.57(.81)$ & $2.56(.71)$ & $2.55(.74)$ & $2.58(.77)$ \\
\hline Personal behavior blame & $1.40(.51)$ & $1.52(.53)$ & $1.53(.54)^{\mathrm{a}}$ & $1.41(.51)^{b}$ \\
\hline Picks on others & $1.42(.40)^{\mathrm{a}}$ & $1.62(.51)^{b}$ & $1.63(.49)^{\mathrm{a}}$ & $1.43(.44)^{\mathrm{b}}$ \\
\hline Close $\mathrm{TSR}^{2}$ & $3.18(.56)$ & $3.11(.58)$ & $3.00(.56)^{\mathrm{a}}$ & $3.28(.56)^{\mathrm{b}}$ \\
\hline
\end{tabular}

Note. ${ }^{1}$ TRBS $=$ Teacher Response to Bullying Schema. ${ }^{2}$ TSR $=$ Teacher-Student Relationship.

Means denoted by different letters indicate significant main effect differences. 
Table 3

Regression Results Predicting “Telling the Teacher" (unstandardized $\beta$ weights)

\begin{tabular}{|c|c|c|c|c|}
\hline Predictor & $R^{2}$ & $\Delta R^{2}$ & $\beta$ & $t$-statistic \\
\hline Step 1 & .19 & & & \\
\hline School & & & .04 & .89 \\
\hline Classroom Climate & & & -.55 & $-4.38^{* * *}$ \\
\hline Grade & & & -.04 & -.30 \\
\hline Sex & & & .21 & $2.17^{*}$ \\
\hline Step 2 & .34 & .15 & & \\
\hline Tell to ignore & & & .09 & 1.09 \\
\hline Tell to assert & & & .06 & .62 \\
\hline Separate students & & & .17 & $2.38^{*}$ \\
\hline Punish aggressor & & & -.14 & $-2.05^{*}$ \\
\hline Involve parents & & & .35 & $4.13^{* * *}$ \\
\hline Personal blame & & & -.08 & -.91 \\
\hline Picks on others & & & -.10 & -.93 \\
\hline Close relationship & & & .07 & .81 \\
\hline
\end{tabular}

Note. ${ }^{*} p<.05$ 


\section{References}

Aceves, M. J., Hinshaw, S. P., Mendoza-Denton, R., \& Page-Gould, E. (2010). Seek help from teachers or fight back? Student perceptions of teachers' actions during conflicts and responses to peer victimization. Journal of Youth and Adolescence, 39(6), 658-669. doi:10.1007/s10964-009-9441-9.

Baldwin, M. W. (1997). Relational schemas a source of if-then self-inference procedures. Review of General Psychology, 1(4), 326-335. doi:10.1037/1089-2680.1.4.326

Baumeister, R. F. (1982). A self-presentational view of social phenomena. Psychological Bulletin, 91, 3-26.

Birch, S. H., \& Ladd, G. W. (1997). The teacher-child relationship and children's early school adjustment. Journal of School Psychology, 35, 61-79. doi:10.1016/S00224405(96)00029-5

Birch, S. H., \& Ladd, G. W. (1998). Children's interpersonal behaviors and the teacher-child relationship. Developmental Psychology, 34, 934-946. doi:10.1037/0012-1649.34.5.934

Bonanno R. A., \& Hymel, S. (2010). Investigating why some victims of bullying are at greater risk for suicidal ideation. Merrill-Palmer Quarterly, 56(3), 420-440. doi:10.1353/mpq.0.0051

Christie-Mizell, C. A. (2004). The immediate and long-term effects of family income on child and adolescent bullying. Sociological Focus, 37(1), 25-41. Retrieved from http://www.jstor.org/stable/20832219

Craig, W. M., Pepler, D. J., Murphy, A., \& McCuaig-Edge, H. (2010). What works in bullying prevention? In E. M. Vernberg \& B. K. Biggs (Eds.), Preventing and treating bullying and victimization (pp. 215-241). New York, NY: Oxford University Press. 
Crothers, L. M., Kolbert, J. B., \& Barker, W. F. (2006). Middle school students' preferences for anti-bullying interventions. School Psychology International, 27(4), 475-487. doi:10.1177/0143034306070435

Dweck, C. S., \& London, B. (2004). The role of mental representation in social development. Merrill-Palmer Quarterly, 50, 428-444. Doi:10.1353/mpq.2004.0029.

Eliot, M., Cornell, D., Gregory, A., \& Fan, X. (2010) Supportive school climate and student willingness to seek help for bullying and threats of violence. Journal of School Psychology, 48, 533-553. doi:10.1016/j.jsp.2010.07.001

Goodenow, C. (1993). Classroom belonging among early adolescent students: Relationships to motivation and achievement. The Journal of Early Adolescence, 13, 21-43. doi: 10.1177/ 0272431693013001002

Graham, S. (2006). Peer victimization in school: Exploring the ethnic context. Current Directions in Psychological Science, 15(6), 317-321. doi:10.1111/j.1467-8721.2006.00460.x

Graham, S., \& Juvonen, J. (1998). Self-blame and peer victimization in middle school: an attributional analysis. Developmental psychology, 34(3), 587. doi:10.1037//00121649.34.3.587

Hamre, B. K., \& Pianta, R. (2001). Early teacher-child relationships and the trajectory of children's school outcomes through eighth grade. Child Development, 72, 625-638. doi:10.1111/1467-8624.00301

Hamre, B. K., \& Pianta, R. C. (2005). Can instructional and emotional support in the first-grade classroom make a difference for children at risk of school failure? Child Development, 76(5), 949-967. doi:10.1111/j.1467-8624.2005.00889.x 
Hawkins, D. L., Pepler, D. J., \& Craig, W. M. (2001). Naturalistic observations of peer interventions in bullying. Social Development, 10, 512-527. doi:10.1111/1467-9507.00178

Hazler, R. J., \& Hoover, J. H. (1993). What do kids say about bullying? Education Digest, 58(7), 16. Retrieved from http://www.eddigest.com

Heilbron, N., \& Prinstein, M. J. (2010). Adolescent peer victimization, peer status, suicidal ideation, and nonsuicidal self-injury. Merrill-Palmer Quarterly, 56(3), 388-419. doi:10.1353/mpq.0.0049

Hox, J.J. (2002). Multilevel analysis: Techniques and applications. Mahwah, NJ: Erlbaum.

Juvonen, J., Wang, Y., \& Espinoza, G. (2011). Bullying experiences and compromised academic performance across middle school grades. Journal of Early Adolescence, 31(1), 152-173. doi:10.1177/0272431610379415

Klomek, A. B., Marrocco, F., Kleinman, M., Schonfeld, I. S., \& Gould, M. S. (2007). Bullying, depression and suicidality in adolescents. American Academy of Child and Adolescent Psychiatry, 46(1), 40-49. doi:10.1097/01.chi.000242237.84925.18

Kochenderfer-Ladd, B. (2003). Identification of effective and adaptive responses to peer victimization among elementary school-aged children. Grant awarded by the National Science Foundation (NSF: Social Psychology BCS 0319462)

Kochenderfer, B. J., \& Ladd, G. W. (1996a). Peer victimization: Cause or consequence of children's school adjustment difficulties? Child Development, 67, 1293-1305. doi:10.1111/j.1467-8624.1996.tb01797.x 
Kochenderfer, B. J., \& Ladd, G. W. (1996b). Peer victimization: Manifestations and relations to school adjustment in Kindergarten. Journal of School Psychology, 34(3), 267-283. doi:10.1016/0022-4405(96)00015-5

Kochenderfer-Ladd, B. J., \& Pelletier, M. E. (2008). Teachers' views and beliefs about bullying: Influences on classroom management strategies and students' coping with peer victimization. Journal of School Psychology, 46(4), 431-453. doi:10.1016/j.jsp.2007.07.005

Kochenderfer-Ladd, B. J., \& Skinner, K. (2002). Children's coping strategies: Moderators of the effects of peer victimization? Developmental Psychology, 38(2), 267-278. doi:10.1037/00121649.38.2.267

Ladd, G. W., \& Kochenderfer-Ladd, B. (2002). Identifying victims of peer aggression from early to middle childhood: Analysis of cross-informant data for concordance, estimation of relational adjustment, prevalence of victimization, and characteristics of identified victims. Psychological Assessment, 14, 74-96. doi:10.1037/1040-3590.14.1.74

Ladd, G. W., \& Troop-Gordon, W. (2003). The role of chronic peer difficulties in the development of children's psychological adjustment problems. Child Development, 74(5), 1344-1367. doi:10.1111/1467-8624.00611

Leary, M. R., \& Kowalski, R. M. (1990). Impression Management: A literature review and twocomponent model. Psychological Bulletin, 107, 34-47.

Nicolaides, S., Toda, Y., \& Smith, P. K. (2002). Knowledge and attitudes about school bullying in trainee teachers. British Journal of Educational Psychology, 72, 105-118. doi:10.1348/000709902158793 
Novick, R. M., \& Isaacs, J. (2010). Telling is compelling: the impact of study reports of bullying on teacher intervention. Educational Psychology, 30(3), 283-296. doi:10.1080/01443410903573123.

Oliver, C., \& Candappa, M. (2007). Bullying and the politics of telling. Oxford Review of Education, 33(1), 71-86. doi:10.1080/03054980601094594

Otieno, T., \& Choongo, H. (2010). Disruptive behavior: Prevalence, gender, and impact of bullying in schools. Journal of Intercultural Disciplines, 8, 98-115. Retreived from

\section{http://www.naaas.org}

Pianta, R.C. (2001). Student-teacher relationship scale. Lutz, FL: Psychological Assessment Resources Inc.

Rock, P.F., \& Baird, J.A. (2012). Tell the teacher or tell the bully off: Children's strategy production for bystanders to bullying. Social Development, 21(2), 414-424. doi:10.1111/j.1467-9507.2011.00627.x

Rose, A. J., Schwartz- Mette, R. A., Smith, R. L., Asher, S. R., Swenson, L. P., Carlson, W., \& Waller, E. M. (2012). How girls and boys expect disclosure about problems will make them feel: Implications for friendships. Child development, 83(3), 844-863. doi:10.1111/j.14678624.2012.01734.x

Rubin, D. B. (1987). Multiple imputation for nonresponse in surveys. Wiley \& Sons: New York.

Smith, J. D., Schneider, B. H., Smith, P. K., \& Ananiadou, K. (2004). The effectiveness of whole-school antibullying programs: A synthesis of evaluation research. School psychology review, 33(4), 547-560. 
Smith, P. K., \& Shu, S. (2000). What good schools can do about bullying: Findings from a survey in English schools after a decade of research and action. Childhood, 7(2), 193-212. doi:10.1177/0907568200007002005

Strohmeier, D. \& Noam, G. G. (Guest Editors)(2012). Evidence-based bullying prevention programs for children and youth. [Special Issue]. New Directions for youth development: Theory, Practice, Research.

Troop-Gordon, W., \& Quenette, A. (2010). Children's perceptions of their teacher's responses to students’ peer harassment. Merrill-Palmer Quarterly, 56(3), 333-360. doi:10.1353/ mpq.0.0056

Visconti, K. J., Kochenderfer-Ladd, B., \& Clifford, C. (2013). Children's attributions for peer victimization: A social comparison approach. Journal of Applied Developmental Psychology, 277-287.

Yoon, J. S., \& Kerber, K. (2003). Bullying: Elementary teachers' attitudes and intervention strategies. Research in Education, 69, 27-35. doi:10.7227/RIE.69.3 